\title{
DISEÑO EMERGENTE EN UNA SOCIEDAD DE CONSUMO EN TAMPICO, MÉXICO.
}

\author{
Víctor M. García Izaguirre, \\ Rebeca I. Lozano Castro \& \\ María Luisa Pier Castelló.
}

\section{Resumen}

Al paso de los años la frontera de México con Estados Unidos ha tenido una serie de transformaciones socioculturales y del paisaje urbano. Bajo esa premisa este estudio de investigación doctoral pretende analizar estos hechos a partir de la historia y la evolución del diseño en esa sociedad de consumo, para generar un marco referencial que pueda encauzar las políticas públicas orientadas por la cultura como motor de cohesión social, identidad local y promoción de valores.

Palabras clave: Diseño, consumo, paisaje urbano, sustentabilidad.

Keywords: Design, consumer, urban landscape, sustainability. 


\section{A lo largo de su historia, México ha sufrido grandes cambios políticos, 4 económicos y sociales. Al inicio de la primera década de 2000 y hasta} nómico. Sin embargo, en el caso de la frontera norte de la República Mexicana, en especial la zona sur del estado de Tamaulipas, se ha observado una tendencia de transformación de lo nacional a lo transnacional, que se ha visto manifestada por ejemplo en la digitalización y mediatización de los procesos culturales en producción, circulación y consumo, que se traducen en control económico y cultural, lo que genera cambios en los valores, hábitos, costumbres, indumentaria y lenguaje en la sociedad y espacio urbano. Algunos países divulgan el consumo en los grandes centros comerciales y a través de su cultura, situación que posee indirectamente intensiones de dominio a través de la mediatización, el marketing y la publicidad, dejando a un lado la identificación con lo artesanal y lo tradicional del país.

Bajo el apoyo del diseño y la sociología se pretende analizar e interpretar las diferentes ideologías para que ayuden a articular una postura conducente y sustentable desde el diseño y así poder contribuir de manera reflexiva, racional y crítica a partir de una realidad social a un esquema evolutivo de cómo se ha transformado el diseño y ha generado cambios culturales en ese sector del país.

La zona sur del Estado de Tamaulipas, en la ciudad de Tampico, cuenta con 3,268,554 de habitantes según la estadística del INEGI (Instituto Nacional de Estadística y Geografía) al 2010. Esta ciudad es conocida por ser uno de los puertos industriales e históricos más importantes de México. Este puerto era la entrada y salida de intelectuales importantes a nivel nacional e internacional. Tampico fue una ciudad en la que la compra, venta, arrendamiento de pozos y terrenos, generó actividades que concentraban un considerable volumen de capital extranjero y mexicano.

Con una postura influenciada por la cultura estadounidense a través de la mediatización, mercadotecnia y publicidad, la sociedad de Tampico se ha ido transformando en una sociedad de consumidores, con una cultura capitalista en donde las actividades de entretenimiento, recreación y pasatiempos se pueden satisfacer en muchas ocasiones mediante la asistencia a centros comerciales o shoppings en su mayoría. Un ejemplo de ello, es la asistencia a lugares de consumo como restaurantes, bares, cafeterías y grandes almacenes, con la intención de pasar un rato de convivencia, dejando de cierta manera en el olvido las plazas, cafés tradicionales, parques y centro histórico de la ciudad. La indumentaria en la sociedad también se ha visto transformada, cuando los jóvenes portan ciertas marcas estadounidenses que están de moda en ese momento y que se encuentran a la venta en todos los comercios de la ciudad.

Bajo ese contexto, el diseño en la zona en la actualidad ha dejado de ser del todo espontáneo y se apega mayormente a profesionales que lo realizan, aunque muchas veces son también personas aficionadas que por medio de recursos tecnológicos realizan estos diseños.

El paisaje urbano es variante aunque predomina el estilo estadounidense dis- 
tribuido en el sector antiguo de la ciudad en el cual se encuentra el centro histórico. La transformación que se ha venido originando en esta zona se ha visto diferenciada por el establecimiento de comercios estadounidenses construidos entre los hermosos edificios de finales del siglo XIX y principios del siglo XX de influencia europea. Además de ello es de suma importancia mencionar el acceso principal a este sector histórico al cual se le conoce con el nombre de Avenida Hidalgo, la cual atraviesa la ciudad de principio a fin y donde se puede observar un panorama tradicional y de comercios extranjeros con el diseño y arquitectura característica del país vecino.

Como apertura comercial y globalizadora, desde el 1 de enero de 1994 que se firmó el Tratado de Libre Comercio entre Estados Unidos de América, Canadá y Mé$\mathrm{xico}^{2}$, se presentaron cambios importantes en perspectivas del mercado, la economía, la política, lo social, la cultura, la tecnología y la ciencia; lo que trajo incertidumbre social en aspectos como el debilitamiento de los lazos de tradición y costumbres en algunas zonas del país. Considerando el concepto de globalización que suele utilizarse genéricamente para legitimar todo tipo de procesos culturales, económicos y políticos que pretenden expresar el progreso de la humanidad (Borja, 2012), se dan ocasiones en donde el impacto es de manera desigual en algunos países y dentro de estos según la zona, lo que provoca fenómenos del proceso de interacción. Por un lado se pueden mencionar las ventajas que esto ha producido en cuanto a Tecnologías de la Información y la Comunicación (TIC) ${ }^{3}$, aperturas de redes globales y mayor fluidez económica e inclusión cultural a nivel global. Sin embargo, también se han generado aspectos en el incremento de la desigualdad social, expresiones propias del lenguaje y consumo globalizado.

Esta cultura de consumo supone la distribución de los bienes culturales e inclusive los signos e imágenes mediáticas que hacen de la conciencia un ritual en donde lo que se obtiene, más que un servicio y producto es una fantasía con sentido de realidad virtual. Nos dice Colin Campbell, "particularmente importante por no decir central" en la vida de la mayoría de las personas, "el propósito mismo de su existencia" es un consumo "para ser" que está asociado a la eternidad del instante de la cultura (2004, p. 27). Por lo cual, en una sociedad lo importante es la naturaleza de un ambiente y sistema estable en donde las influencias de cualquier tipo que se generen, el entorno las vaya absorbiendo, adoptando y ajustando a sus condiciones poco a poco para no verse afectado.

El diseño de consumo sin lugar a duda ha generado una transformación social y cultural de la cual se pueden ver los efectos de la modernidad en convivencia con las tradiciones propias de cada lugar. Diseño y medios de comunicación se convierten así en piezas indispensables de la maquinaria que sostiene el orden económico de cualquier país. El diseño orientado al consumo, entendido de modo muy genérico como el instrumento necesario para formalizar los objetos industriales en productos consumibles, tiene también por misión visualizar valores y creencias en un mercado competitivo sujeto a fuertes tensiones, además de facilitar la ubicación de lo que se 
quiere vender en la mente de los compradores y formalizar en los objetos comerciales aquello que da satisfacción a sus necesidades y emociones (Vega, E. 2011). Este tipo de diseño de consumo manifiesta las ventajas y desventajas que se derivan de la adquisición de los productos o servicios colocándose como respuesta a sus anhelos, aspiraciones o creencias características de ciertos sectores sociales de acuerdo al país; economía, política y demás aspectos culturales que estén aconteciendo en este momento. Que en ocasiones se percibe una posición de competencia difícil para aquellas empresas locales que deben competir con el mercadotecnia y la mediatización de las corporaciones franquicitarias.

La globalización crea un terreno favorable para el desarrollo y proliferación de algo, y ese algo es fácilmente globalizado. La zona norte de México es claro ejemplo de ello, se percibe como ciudades con estilo estadounidense en su paisaje urbano y algunas tradiciones que forman parte de su cultura, aunque no se puede hablar de una generalidad social. Pablo R. Cristoffanini (2006) habla del dominio generado por Estados Unidos en la difusión de la mentalidad, hábitos y prácticas; la implementación de ideas centrales de utopía neoliberal (importaciones, privatización, disminución del rol del Estado, etc.) con la idea de promover la modernización de la sociedad. Este cambio considera el consumo de bienes importados garantizando la apertura de mercados; estrategia de avance social y realización personal. En el plano de la cultura material y simbólica ha significado la influencia de la cultura norteamericana (estadounidense propiamente dicha); la televisión, el cable y el internet con publicidad para generar necesidades, remarcar las virtudes de productos importados y promover estilos de consumo.

De acuerdo con lo anteriormente relacionado se prevé la importancia de generar un estudio sobre estos cambios desde el diseño como acción reflexiva y de análisis de la evolución histórica y socio-cultural, además que venga a ser un referente histórico del cual aún no se haya tenido en México y el mundo. Se pretende estudiar a partir de nuevos paradigmas del diseño que ayuden a comprender mejor aspectos sociales como el consumo para analizar los efectos y reacciones que hayan generado tales cambios y transformaciones en esa sociedad. En esta contribución de conocimiento que se llevará a cabo, no solo tendrá impacto en la disciplina (diseño) de cómo se ha sido transformado bajo su propia naturaleza evolutiva y de modernidad, sino también los estilos y el contexto social que lo influenciaron. Un beneficio de lo que se puede obtener con una investigación de esta índole es la concepción de nuevas teorías y conceptos que partan de referentes documentados, y que sirvan de argumentos confiables para el diseño de consumo o de otra especialidad; por ejemplo el diseño de servicios considerando la eficacia y eficiencia en el mercado, donde se diseña estratégicamente para y con el usuario, haciendo uso de su participación e interacción desde el proceso de innovación y diseño. La importancia estratégica del diseño como gestor social del conocimiento y lo que lleva al análisis profesional de la información y su transformación puede convertirse en un vector de la actividad mediática. 
Es importante que a partir del análisis evolutivo del diseño y la sociedad, se genere un testimonio histórico que pueda posteriormente encauzar las políticas públicas orientadas por la cultura como motor de cohesión social, identidad local y promoción de valores; donde se puedan tomar consideraciones en la transformación del paisaje urbano revalorando los edificios que son parte del patrimonio en la ciudad, capitalización de algunos de sus elementos culturales y construcción de íconos en torno a una cultura fronteriza híbrida, transformada y rentable para todo el país, integrando los diversos saberes en pro de la mejora en la calidad de vida. Cuando se analiza la cultura de una sociedad, no se debe dejar a un lado el aspecto de la educación desde su estructura según el contexto en el cual se esté implementando. Al respecto se pueden mencionar ciertas medidas emergentes que han servido de apoyo al diseño en la cultura y la sociedad.

La interrelación de ciertas áreas presentes a través del tiempo y de los estilos pueden permitir llevar a cabo un análisis crítico que sacando a la luz sus implicaciones sociales discuta la verdadera razón de ser del diseño, como un instrumento de comunicación de utilidad pública que apoye a las políticas públicas actuales orientadas hacia la cultura como un motor de cohesión social e identidad local promoviendo los valores en la ciudadanía, transformando el tejido urbano por medio de la valoración del patrimonio histórico, la capitalización de sus elementos culturales en una cultura híbrida y rentable. Considerando los antecedentes que preceden y esta postura actual social en donde percibimos una poca exaltación cultural en México que permita soportar la influencia extranjera en el diseño de consumo, se plantearon las siguientes interrogantes al margen de la problemática y que serán el eje central de nuestro estudio: ¿Cuáles son los componentes y estrategias de diseño tampiqueño que podrían ayudar a contrarrestar la influencia cultural extranjera? Para ello deberemos proponer soluciones que ayuden a generar respuestas positivas para contrarrestar la influencia estadounidense del diseño de consumo a la cultura mexicana en Tampico.

Partiendo de que el concepto de emergente surge de un significado el cual denota un cambio "que nace, sale y tiene principio de otra cosa" (RAE, 2014), considerándolo desde la evolución y transformación, en la historia del diseño y la sociedad. Por lo cual, se puede relacionar el desarrollo desde dos perspectivas paralelas que en ciertos puntos se unirán y complementarán. Por un lado se encontró implementado el Tratado de Libre Comercio y la influencia estadounidense en un país que no estaba preparado socio-culturalmente para asumir esos cambios en su cultura. Y por otro lado, el aspecto del entorno urbano, el cual se ha visto transformado desde la perspectiva del paisaje histórico que lo caracterizaba. Por ello, se pretende que de este estudio se deriven nuevas estrategias para comprender mejor y poder generar acciones que beneficien a la sociedad, desde el diseño.

El hecho de analizar a una sociedad en particular como esta, exalta la importancia de estudiar el consumo de influencia extranjera y de cómo transforma los diversos aspectos económicos, políticos y culturales de la zona. Como menciona N. García 
Canclini, a los procesos globalizadores que amplían las facultades combinatorias de los consumidores pero casi nunca la "hibridación endógena", y si por el contrario una "hibridación heterónoma", combinándose en una degeneración de mensajes y de bienes del sentido social (2001). Actualmente Canclini define al concepto de hibridación como aquel que se le da a un término de traducción entre mestizaje, sincretismo, fusión y los otros vocablos empleados para designar mezclas particulares. De igual manera, son los procesos socioculturales o prácticas discretas que ya existían en forma separada y después se combinaban para generar nuevas estructuras, objetos y prácticas. Es decir, ambivalencias de la industrialización y masificación globalizada de los procesos simbólicos. Al referirse a México, lo define como una articulación compleja de tradiciones y modernidades desiguales con lógicas múltiples de desarrollo; tradición, etnicismo y nacionalismo (Ib. 1995). Es para reflexionar si el acceso a la variedad de bienes y la capacidad de combinarlos nos ayudan a un desarrollo cultural y bajo qué pregnancia, considerando la multiculturidad en los procesos socioculturales y cómo pasan de formas de cultura más simples a otras más complejas, y así sucesivamente sin quedar una como pura o plena. La identidad se concluye como una fase de la abstracción de los rasgos más característicos de ciertas culturas a través de la historia, siendo una conjunción de medios simbólicos. También hay que considerar cómo la modernidad puede generar un desgaste del patrimonio étnico y nacional hasta la transformación de sus costumbres y de cómo lo transnacional tiene influencia en lo nacional, y del control económico y cultural al que se ha llegado.

A decir de Bourdieu (2012), se considera al consumo como un espacio de significado que de acuerdo a su teoría no puede reducirse a la presencia de distinciones sociales, sino también se relaciona con aspectos aspiracionales de aceptación, integración y seguridad. Sin embargo, si el consumo aparece como centro de las estrategias puede generar distinción social desplegada por los grupos y la dimensión simbólica, y también en la construcción de las jerarquías sociales como posición o prestigio dentro del espacio social. Al considerar este análisis desde el contexto sociohistórico en las diferentes formas de pensar lo social y del consumo, su propuesta de mapa de gustos y prácticas culturales por sobre el nivel del capital económico y varios aspectos del escenario social como la construcción identitaria o sistema de valores, que apoyen a comprender mejor las acciones actitudinales de esa sociedad (Ib.). El autor concluye que la hibridación en la cultura de consumo es consecuencia de una modernidad innegable como establecimiento entre las tradiciones excluyentes o influyentes y donde la sociedad necesita gestionar lo imaginario para que a partir de ello surjan una serie de valores intangibles propios y distintivos de las raíces de esa localidad.

Estos y otros modelos pueden ser utilizados desde su análisis para la construcción de una teoría propia. Sin embargo, en el aspecto analítico del diseño lo apoyarán elementos mucho menos tangibles como construcciones sociales, simbolismos y nuevos imaginarios urbanos. Yes importante mencionar también en esta fase teórica la diferencia cuando me refiero a diseño (de manera general) y diseño de consumo 
(o para una cultura de consumo de manera particular), ya que puede prestarse a una confusión en su aplicación. Diseñar es coordinar una larga lista de factores humanos y técnicos, trasladar lo visible en visible y comunicar. Diseñar implica evaluar, implementar ideas, generar nuevos conocimientos y usar la experiencia para guiar la toma de decisiones; planificar para obtener un propósito específico perseguido. El diseño es el proceso de concebir, programar, proyectar, coordinar, seleccionar y organizar una serie de factores y elementos -normalmente textuales y visuales- con miras a la realización de productos destinados a producir comunicaciones visuales; objetos creados ${ }^{4}$. Explicar el diseño desde el contexto socio-cultural puede derivarse en un fenómeno urbano en el que se haya tenido todo tipo de influencias además de factores tecnológicos, estéticos, simbolización, iconicidad y patrimonio histórico. Este conjunto de narrativas pueden ser consideradas desde su historia y transformación. Es entonces cuando se podrá utilizar el concepto de diseño aplicado a la imagen de una ciudad y comprender estructuralmente a esa sociedad en sus conductas, valores, problemáticas, entre otras para el desarrollo de una sustentabilidad social deseable.

\section{Conclusiones}

Este proyecto de investigación se encuentra en proceso de ejecución, y se pretende con él lograr, a partir del estudio de nuevos paradigmas del diseño, ayudar a comprender mejor y así optimar aspectos de índole social como lo es el consumo. De tal forma que analizar los efectos y reacciones que hayan generado tales cambios y transformaciones en esa sociedad mexicana sustenten una mejor calidad de vida en los habitantes de esa sociedad. Dicho estudio será una contribución al conocimiento teniendo un impacto tanto en el diseño como en el aspecto sustentable, social y del cual se derivará un análisis profesional estratégico de diseño como gestor social y vector mediático. 
Notas

1. Instituto Nacional de Estadística y Geografía (INEGI). Estadística Poblacional al 2010. Disponible en: http://www.inegi.org.mx

2. Tratado de Libre Comercio de América del Norte (TLC). North American Free Trade (NAFTA). El Tratado de Libre Comercio de América del Norte entre EEUU, Canadá y México entró en vigor el 1 de enero de 1994, una vez concluidos los procedimientos internos de aprobación. Web. 29 de octubre 2015. Recuperado en: http://www.americaeconomica.com/portada/bloques/nafta.htm

3. TICS - Tecnologías de Información y Comunicación. Conjunto de tecnologías que permiten la adquisición, producción, almacenamiento, tratamiento, comunicación, registro y presentación de informaciones. Recuperado el 1 de noviembre 2015 en: http://www.monografias.com/trabajos89/tics-tecnologias-informacion-y-comunicacion/tics-tecnologias-informacion-y-comunicacion.shtml

4. Jorge Frascara, El Diseño de Comunicación, edición corregida y extendida de Diseño Gráfico y Comunicación, 2015, p. 23.

\section{Referencias bibliográficas}

Alonso Recarte, C. (2011). Estrategias de marketing, consumismo y el ejercicio democrático en Adventures in the Wilderness; or, Camp-Life in the Adirondacks de W.H.H. Murray. Atlantis, revista de la Asociación Española de Estudios Anglo-Norteamericanos, Recuperado de http://go.galegroup. $\mathrm{com} / \mathrm{ps} / \mathrm{i} . \mathrm{do}$ ?id=GALE\%7CA260873462\&v=2.1\&u=up_web\&it=r\&p=GPS\&sw=w\&asid=09db6a2fa3327619c74647d48f34f5a2

Altamirano, C. \& Sarlo, B. (1993). Literatura/Sociedad. Buenos Aires: Edicial.

Belting, H. (2007). Antropología de la imagen. Buenos Aires: Katz.

Benedetti, C. (2012). Diferencias y desigualdades: reflexiones sobre identidad étnica y producción artesanal chané destinada a la comercialización. Recuperado de http://www.scielo.org.mx/pdf/alte/ v22n43/v22n43a3.pdf

Borja, J. (2012). La ecuación virtuosa e imposible o las trampas del lenguaje en Carajillo de la ciudad. Revista digital del Programa en Gestión de la Ciudad. Universitat Oberta de Catalunya. Año 4. Recuperado de http://cafedelasciudades.com.ar/carajillo/12_art3.htm

Bourdieu, P. (2012). La distinción. Criterio y bases sociales del gusto. Buenos Aires: Taurus.

Cambell, C. (2004). I shop therefore I know that I am: The metaphysical basis of modern consumerism. En Karin M. Ekström y Helene Brembeck (eds.), Elusive Consumption, Nueva York.

Cháves, N. (2001). El oficio de diseñar. Propuestas a la conciencia crítica de los que comienzan. BarceIona: Gustavo Gili.

Costa. J. (1992). Imagen Pública. Una ingeniería social. Madrid: FUNDESCO.

Costa, J. (2015). La Comunicación y las Ciencias de la Acción. Barcelona: Paidós.

Cristofanni, R. (2006). La cultura de consumo en América Latina. Sociedad y discurso. No 10. (Tesis de Doctorado). Aalborg Universitet. Chile. Recuperado de http://amalthea.aub.aau.dk/index.php/sd/ article/download/816/641 
Díaz, E. (1996). La Ciencia y el imaginario social. Buenos Aires: Biblos.

Frascara, J. (2006). El Diseño de Comunicación. Edición corregida y extendida de Diseño Gráfico y Comunicación. Buenos Aires: Infinito.

Frascara, J. (2008). Diseño Gráfico para la gente. Buenos Aires: Infinito.

García Canclini, N. (1995). Consumidores y ciudadanos. Conflictos multiculturales de la globalización. México: Grijalbo.

García Canclini, N. (2001). Culturas Híbridas y Estrategias Comunicacionales. Buenos Aires: Paidós.

Klein, N. (2015). No Logo: el poder de las marcas. Buenos Aires: Paidós.

Ledesma, M. (2003). El diseño gráfico, una voz pública. Buenos Aires: Argonautas.

Munari, B. (2010). ¿Cómo nacen los objetos? Barcelona: Gustavo Gili.

Norman, D. (2005). Diseño Emocional. Barcelona: Paidós.

Ofenhender, S. (2015). Mundo Líquido. Recuperado de

http://www.pensesarau.com.br/artigos/reconstruindo_futuro_andrea_soledad_PORT.pdf

Ortega, B. (2000). In Sam we trust. United States of América: Three Rivers Press.

Parera, D. T. (2010). Diseño Gráfico y Comunicación. Madrid: Pearson Educación S.A.

Pelta, R. (2004). Diseñar Hoy. Barcelona: Paidós.

Popper, K. (1994). En busca de un mundo mejor. Barcelona: Paidós Ibérica.

Real Academia Española, Diccionario de la lengua española, 23. ${ }^{a}$ ed. (2014). "Emergente". Madrid:

Espasa. Recuperado de $h t t p: / / d l e . r a e . e s / ? w=$ emergente\&m $=$ form $\& 0=h$

Sarlo, B. (1994). Escenas de la vida posmoderna, intelectuales, arte y videocultura en la Argentina. Buenos Aires: Ariel.

Sarlo, B. (2009). La ciudad vista. Mercancías cultura urbana. Buenos Aires: Siglo XXI.

Sassatelli, R. (2007). Consumer Culture. History, Theory and Politics. London: Sage.

Sparke, P. (2014). Diseño y cultura. Una introducción desde 1900 hasta la actualidad. Madrid: Gustavo Gili.

Vega, E.(2011) Diseño para el consumo. Escuela de arte Nº. 10. Paperback. Recuperado de http://eprints. ucm.es/13968/1/consumer.pdf

Weber, M. (2002). Economía y Sociedad. Esbozo de sociología comprensiva. Madrid: Fondo de Cultura Económica de España. 